\title{
Osteoid Osteoma in Fourth Finger
}

\author{
Masoud Shayesteh Azar ${ }^{1}$; Mohammad Hossein Kariminasab ${ }^{1}$; Mohamd Mehdi \\ Daneshpoor ${ }^{1, *}$; Shadi Shayesteh Azar ${ }^{2}$ \\ ${ }^{1}$ Department of Orthopedic, Mazandaran University of Medical Sciences, Sari, IR Iran \\ ${ }^{2}$ Medical Student, Mazandaran University of Medical Sciences, Sari, IR Iran \\ *Corresponding author: Mohamd Mehdi Daneshpoor, Department of Orthopedic, Mazandaran University of Medical Sciences, Sari, IR Iran. E-mail: mhkariminasab@gmail.com
}

Received: March 12, 2014; Accepted: May 22, 2014

Osteoid osteoma is a benign bone tumor that is composed of osteoid and atypical woven bone. This tumor included 11 - $12 \%$ of all benign skeletal lesions. Overall occurrence of phalangeal osteoid osteoma is rare but in hand is extremely rare. In previous reports involvement of the phalangeal bone of the finger describe only in few cases. In this study, we report a case of a 25 years old man with a 2 months history of pain, enlargement, swelling in proximal phalanx of right fourth finger.

Keywords: Osteoid osteoma; Finger; Tumor

\section{Introduction}

Osteoid osteoma is a relatively benign bone lesion with unknown etiology that present between the ages of 10 and 30 years with a male-female ratio of 2:1 [1]. This common bone tumor, approximately involve $11-12 \%$ of all benign skeletal lesions. It is commonly seen in the long bones of appendicular skeleton, particularly in the femur and tibia [2]. The clinical feature of the lesion is local pain, usually more severe at night and this pain often completely responds to aspirin and other NSAIDs [2,3]. The usual radiological feature is bone formation with central nidus of vascular osteoid tissue plus sclerotic bone in rim of this tissue.

On the other hand, this tumor is composed of circular radiolucent zone with nidus and a distinctive surrounding area of sclerosis $[1,2,4]$.

This is a well-recognized tumor that can cause diagnostic difficulties. Previous reports describe cases of osteoid osteoma mismanaged or misdiagnosed as stress fracture, gout, and bacterial or rheumatoid arthritis. A reactive synovitis and effusion may occur that can simulate arthritis without periostitis. It may be difficult to diagnose osteoid osteoma arising in a finger phalanx if the surgeon did not suspect to this tumor $[4,5]$.

Traditionally treatment of this tumor was removal the tumor, with its nidus. Several methods included medical management with NSAIDs and open surgical resection with intralesional, marginal, or wide surgical margins was done by surgeon. Recently, several CT-guided percutaneous techniques have been used to achieve ablation of the nidus $[1,3,5,6]$. We present a patient with osteoid osteoma which presented to our clinic, complaint of pain in the proximal phalanx of his right 4 th finger.

\section{Case Presentation}

A 25-year-old right-hand-dominant man presented to our outpatient clinic with a chief complaint of pain in the proximal phalanx of his right 4 th finger without history of previous trauma or infection involving this finger and negative past medical history.

On the patient's initial visit to our clinic he said that he did not receive any treatment prior to refer to clinic except analgesic drugs.

The pain had been started for approximately 2 months as mild pain that caused into acute tenderness with movement and touch. His pain was relieved with gelofen. Gradually his pain was persistent and increased the severity that caused him to go to the clinic because of rest pain. He felt difficulty in routine task. Other symptom was swelling that localized to the proximal phalanx of his right 4th finger.

On physical examination, there was no clinical abnormality, except the localized swelling and soft tissue enlargement to his right 4 th finger. There was no erythema or induration. There was a little limited range of motion in the proximal interphalangeal or first metacarpophalangeal joint. Neurovascular exam of this upper extremity was normal.

The results of inflammation and rheumatic diseases evaluations laboratory, including $\mathrm{CBC}$, serum chemistries, ANA, Wright, 2ME and others were all within normal limits.

Plain radiographs of the fingers showed soft tissue edema and a well-defined calcified mass eroding the cortex of the distal phalanx.

In order to further clarify the diagnosis, CT scan of the

Copyright (C) 2015, Zahedan University of Medical Sciences. This is an open-access article distributed under the terms of the Creative Commons Attribution-NonCommercial 4.0 International License (http://creativecommons.org/licenses/by-nc/4.0/) which permits copy and redistribute the material just in noncommercial usages, provided the original work is properly cited. 
right hand was done. This modality showed a focal lucent lesion at the proximal phalanx of right 4 th finger with no associated periosteal bone formation (Figure 1). A central nidus and surrounding sclerosis in the adjacent bone was characteristic for diagnosis of an osteoid osteoma.

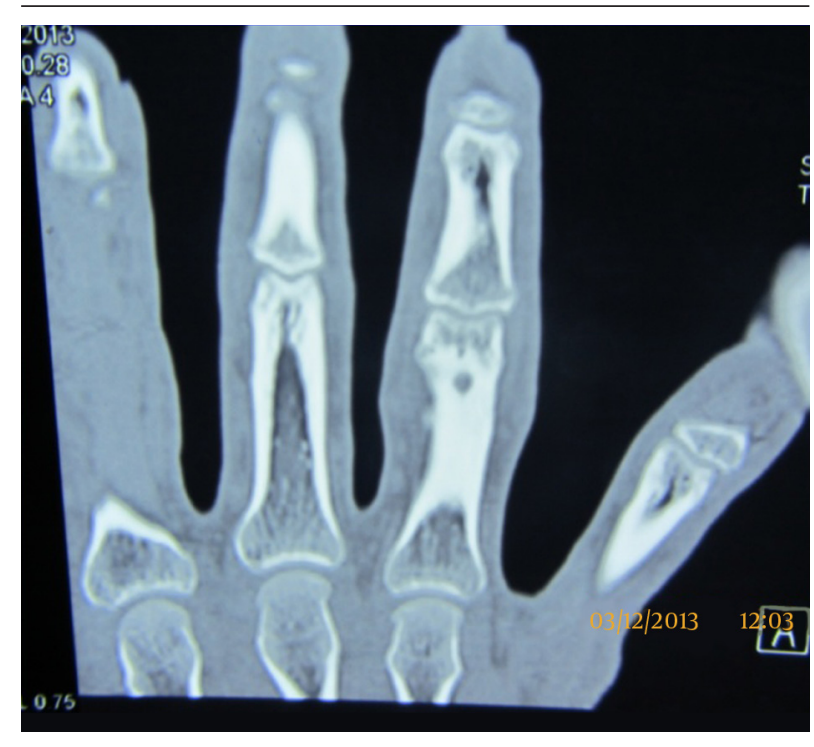

Figure 1. CT Showing a Small Nidus Surrounded by Low-Attenuation Area at Proximal Phalanx of Right 4th Finger

Bone scan was done in the patient showed localized uptake increase at the proximal phalanx of his right 4 th finger.

After a thorough discussion with the patient, we undertake an excisional biopsy of the lesion 1 month after first visit because of removing the lesion and relief the patient's pain and swelling (Figure 2). We excised the lesion completely with curettage and also nidus removed.

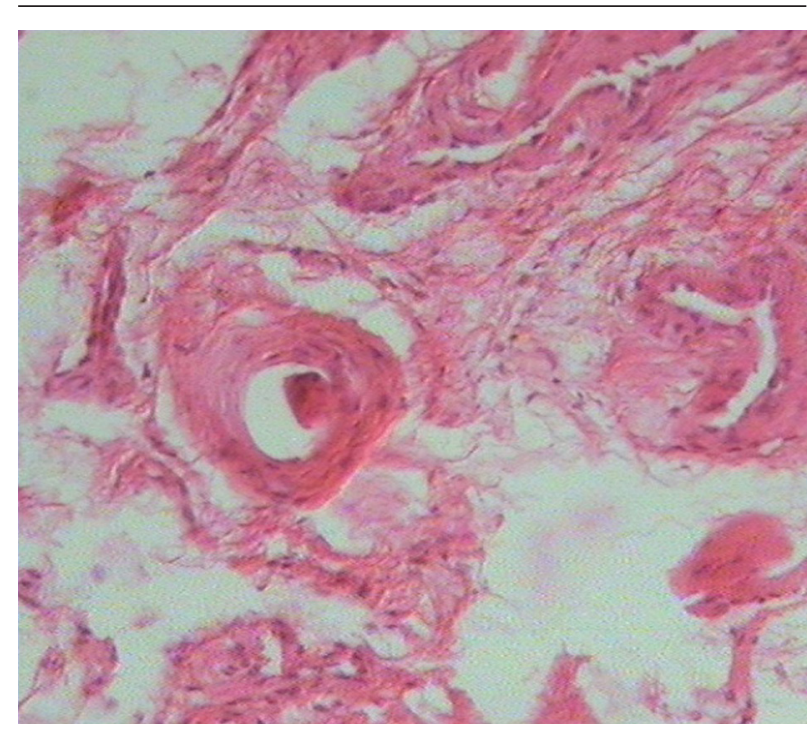

Figure 2. Small and Yellowish to Red Nidus of Osteoid and Woven Bone With Interconnected Trabeculae
At the first postoperative visit, the patient had clear decrease in the pain severity that he was experiencing before the surgery and 2 months after the surgery he had no pain in the tumor site. Finally at final follow-up, 6 months after surgery, the patient described no pain with full use of his hand. We did not see localized swelling in the operated finger. Plain radiograph at this time was normal and resolution of the lesion was seen.

\section{Discussion}

Osteoid osteoma is a common benign bone tumor, often found in children and young adults and its occurrence in the hand is rare. Five percent of all primary bone tumors are composed of osteoid osteoma. The etiology of the disease is unknown [1-3,5].

One of the common problems in this tumor is delaying accurate diagnosis because of the mentioned cause. Other cause is the nidus did not clear on plain radiographs and it may be similar to bony lesions. On the other hand, misdiagnosis or delayed diagnosis is not unusual and it can be misdiagnosed as gout, stress fracture, and bacterial or rheumatoid arthritis. A high index of suspicion is essential for surgeon for the diagnosis of this tumor $[4,6,7]$.

If it occurs in the hand or foot, it can appear in an intraor juxta-articular location. This neoplasm is more common in the long bones and femur or tibia approximately $50 \%$ to $60 \%$ of cases involved $[6,7]$.

Diagnosis in most cases is based on an accurate history of gradual onset of progressive night pain, clinical assessment, radiographic findings and pain relief with NSAID $[5,6]$. An excess of cyclooxygenases and prostoglands within the lesion leads to vasodilation resulting pain sensations. This mechanism reveals that how the drugs named NSAIDs cause pain relief $[7,8]$.

Diagnosis of this disease in hand is too difficult because of localized pain and localized swelling was replaced by vague pain and diffuse swelling in the digits and this atypical symptoms caused that diagnosis of the lesion in uncommon site will be so difficult and delayed diagnosis is more common $[4,8]$.

According to localization, different types of osteoid osteoma have been classified into cortical (most common), cancellous and subperiosteal types. Typically, radiography of affected patients shows a cortically based sclerotic lesion with a small lucent nidus at its centre $[6,7]$.

Technetium bone scans and CT may aid in making the diagnosis when initial radiographs are non-specific. Treatment varies in these patients, include nonsurgical management with NSAIDs, CT-guided percutaneous radiofrequency thermal ablation, and open surgical procedures. Although NSAIDs can cause pain relief in these patients but side effects such as GI discomfort and renal problems cause surgeon to operate patients or use other methods.

Moreover, only few manuscripts reported spontaneous regression or medical treatment was successful in the management of this tumor. The objective of this study 
was to describe the clinical and imaging features of this tumor involving the phalangeal finger, because rare occurrence and difficulties in the diagnosis $[1,3,7,8]$.

\section{Authors' Contributions}

All authors had equal role in design, work, statistical analysis and manuscript writing.

\section{References}

1. Johnson T, Steinbach L. Essentials of musculoskeletal imaging. 1st ed. Illinois: American Academy of Orthopedic Surgeons; 2004.

2. Wang NH, Ma HL, Lo WH, Yang DJ. Osteoid osteoma: clinical and investigative features. J Formos Med Assoc. 1990;89(5):366-72.

3. Sproule JA, Khan F, Fogarty EE. Osteoid osteoma: painful enlargement of the second toe. Arch Orthop Trauma Surg. 2004;124(5):354-6.

4. Barca F, Acciaro AL, Recchioni MD. Osteoid osteoma of the phalanx: enlargement of the toe-two case reports. Foot Ankle Int. 1998;19(6):388-93.

5. Ramos L, Santos JA, Santos G, Guiral J. Radiofrequency ablation in osteoid osteoma of the finger. J Hand Surg Am. 2005;30(4):798802.

6. Zouari L, Bousson V, Hamze B, Roulot E, Roqueplan F, Laredo JD. CT-guided percutaneous laser photocoagulation of osteoid osteomas of the hands and feet. Eur Radiol. 2008;18(11):2635-41.

7. Atesok KI, Alman BA, Schemitsch EH, Peyser A, Mankin H. Osteoid osteoma and osteoblastoma. J Am Acad Orthop Surg. 2011;19(11):678-89.

8. Mori K, Imai S, Saruhashi Y, Matsusue Y. Thoracoscopic en bloc extirpation for subperiosteal osteoid osteoma of thoracic vertebral body: a rare variety and its therapeutic consideration. Spine J. 2011;11(5):e13-8. 